\title{
The effect of different linear robot travel speed on mass flowrate of pineapple leaf fibre (PALF) automated spray up composite
}

\begin{abstract}
This paper investigates the effect of different linear robot travel speed on mass flowrate of bio composites automated spray up. The linear robot travel speed investigated are 0.5, 0.75, 1.0, 1.25 and $1.5 \mathrm{~m} / \mathrm{s}$. In this study, the manual chop spray gun is integrated with industrial robotic arm to produce random discontinuous fibre composite (DFC) from PALF roving (273 tex) and vinyl ester resin. Samples fabricated are tested for mechanical properties including tensile and flexural, and thermal properties including TGA and DMA. The results showed that the speed of $0.75 \mathrm{~m} / \mathrm{s}$ yielded $28.70 \mathrm{MPa}$ of tensile strength, tensile modulus of $3.17 \mathrm{GPa}$, with the lowest Coefficient of Variance (COV) of $9.51 \%$, which denotes the best combination compared to all other robot speed. The flexural test depicted speed of $1.0 \mathrm{~m} / \mathrm{s}$ to be the highest with $59.12 \mathrm{MPa}$ with $18.10 \% \mathrm{COV}$, while speed $0.75 \mathrm{~m} / \mathrm{s}$ produced the best COV of $12.67 \%$ despite lower flexural strength of $55.83 \mathrm{MPa}$. The TGA showed that the $0.75 \mathrm{~m} / \mathrm{s}$ speed sample yielded the highest onset oxidation temperature (OOT) of $392.06^{\circ} \mathrm{C}$ and highest maximum combustion temperature of $433.40^{\circ} \mathrm{C}$. The DMA depicted the highest Glass Transition Temperature $(\mathrm{Tg})$ of $118.20^{\circ} \mathrm{C}$ is also recorded by the $0.75 \mathrm{~m} / \mathrm{s}$ robot speed composite sample.
\end{abstract}

Keyword: Spray up; Bio composite; Natural fibre; Direct fibre compounding; Pineapple leaf; Vinyl ester 